\title{
Optimizing the Skills of Clothing Design Teachers and Students in Clothing Design Using the Coreldraw and Adobe Illustrator Programs to Respond to Industry 4.0
}

\author{
Muh Fakhrihun Na'am ${ }^{1}$, Taofan Ali Achmadi ${ }^{2}$ and Ade Novi Nurul Ihsani ${ }^{3}$ \\ \{fakhri.artworker@mail.unnes.ac.id, taofanali@gmail.com, ade.ihsani@gmail.com\} \\ ${ }^{1}$ Department of Home Economic, Universitas Negeri Semarang, Semarang, Indonesia
}

\begin{abstract}
The creation of technology-based fashion design is a necessity for the effectiveness of learning curriculum for Clothing and Industry 4.0 Vocational Schools, the provision of skills to students is a necessity. Fashion Design which includes the design of body proportions, fashion parts and shapes, sketches by the concept of collages, Adobe Illustrator design offerings, fashion Illustration, sketching designs, and designs production. The Adobe Illustrator CorelDraw program is strategic so that it is relevant to respond to community service activities to develop computer technology-based education because it contributes positively to the skills of fashion education students. A very fundamental problem is the lack of students in innovating in the teaching and learning process based on computer programs. The result of this dedication is the ability of fashion design education department students PKK FT UNNES in creating fashion designs based on the Adobe Illustrator CorelDraw program so that they are able to develop and utilize science and technology for the creation of fashion designs, giving new insights about creating fashion designs with the CorelDraw program and Adobe Illustrator among students so that it attracts a love of fashion design, while at the same time orienting towards regenerating the development of fashion designs in other wider communities, this service is also oriented towards producing scientific articles, copyrights, and reports. To achieve these objectives, this service includes activities such as: literature study, observation, training, workshops, documentation, understanding fashion design with CorelDraw and Adobe Illustrator to students including: the embodiment process, creating fashion designs with CorelDraw Adobe Illustrator data; creating fashion design tutorials using CorelDraw and Adobe Illustrator, registering copyrights; compile report. Disseminating to designers at the Fashion Vocational Schools, result designers, and related institutions; compiling reference books, scientific articles, international journals, copyrights, tutorial books, and reports.
\end{abstract}

Keywords: Creation of fashion design, CorelDRAW, Adobe Illustrator, industry 4.0

\section{Introduction}

Fashion design is very fundamental to the development of fashion itself. Clothing can be said to have quality, philosophical, and economic value because the design elements are very dominant and affect consumers or observers of fashion. The purpose of using a computer as a tool is to simplify work, accelerate the need for information systems, and provide convenience in creating fashion designs by utilizing available computer software. 
The development of fashion designs from various regions has characteristics that highlight the potential in the area. The weakness of some areas is the difficulty in developing existing designs including the academic community. Learning still looks monotonous with various manual techniques and there is no visible digital touch in creating a design. Based on observations made, the weakness of some students is the visual processing that is less attractive and does not utilize existing technology. At least students of fashion design due to lack of experts so that it affects the new fashion design designers utilizing software to process and create relatively few fashion designs. Fashion designers as one of the main actors of fashion companies, in general, have not maximized the existing technology in creating designs. Innovations and creations of fashion designers in the form of fashion designs need to be inventoried by storing existing works to make time and energy-efficient.

Clothing design activities that are generally done manually on paper media can now be done using computers using various software for drawing such as CorelDraw and Adobe Illustrator Macromedia Freehand, Paint, Adobe Photoshop, and AnSeries. CorelDraw and Adobe Illustrator tracing (broken colors) in the textile printing industry can also be used for the design process (textiles). CorelDraw and Adobe Illustrator have advantages in the process of making designs and tracing easily and are instant nature made specifically for fashion design. This software is expected to reduce the burden both in cost and energy in a fairly simple way. Processing fashion design drawings is very helpful for processing these images and will obtain a fashion design. Students are able to process ideas and creativity through this software. It is expected that the method of creating fashion designs using CorelDraw and Adobe Illustrator is part of efforts to strengthen the national innovation system considering the fashion industry is synonymous with national interests because the above problems are also dominantly experienced by the academic community, vocational students, crafters, and fashion industry players in the region Indonesia. Therefore, based on the above problems the objectives of this research are: (1) Can produce a unique, creative design based on CorelDraw and Adobe Illustrator programs that can provide competitive advantages amidst the many designers in the present and the future; (2) Improve the ability to respond to computer programs to design. With the fashion design using CorelDraw and Adobe Illustrator which, besides being practical, unique, creative, innovative, and varied, can also improve the ability of teachers and students in designing with Adobe Illustrator program.

\section{Methods}

This research is a type of experimental research. The sample in this study were 5 Vocational High School Dressmaking teachers and 25 Clothing Design students at the UNNES Faculty of Engineering. The research process is carried out with the following procedures: (1) The community service program begins with the socialization of identification and mapping of targets according to program needs theoretically and methodologically. (2) Establishing solutions that can be explained scientifically in relation to priority issues agreed with the community, or identifying asset-agents in the socio-cultural process of the community. The first thing that was carried out in this series of services was to provide understanding to the Fashion Vocational School teachers in the city of Semarang and the students of fashion education study programs. Conduct training for Semarang City Vocational School teachers and PKK students Fashion Design departement, UNNES, considering that the Adobe Illustrator program has been included in fashion design courses in SMK Fashion Clothing. After understanding the 
participants, the next thing is practice with competent presenters, then it is applied to teaching the students, and for students is the provision that must be had when they have graduated and entered the community.

\section{Results}

Corel Draw program is often used to do jobs such as creating a logo or symbol design, used by its users, especially in making two-dimensional logos because of its ease in processing lines and colors. Adobe Illustrator was chosen because the work of illustration is very powerful and lightweight so it makes the process of making images with digital devices easier than other programs. Full features, such as the screen palette in Adobe Photoshop that graphic designers often use to coordinate screens and the hardware requirements used are not high in installing Adobe Illustrator programs. In addition, the resulting color quality is very good, the color output on the monitor with printouts is almost the same.

Adobe Illustrator is a vector-based image processing software or grapic design program. Vector itself is a collection of points and lines that are connected which is a combination of colors to form a drawing object created by Adobe Systems that uses vectors (Yoga, 2005: 1). As a vector illustration program, Adobe Illustrator is a reliable software to realize the creativity and imagination of a designer in the form of images. This program is highly recommended for use by graphic design circles. Various conveniences in making graphic works can be realized with the help of tools and simple interfaces (Hendratman, 2018: 21). Adobe Illustrator was created in 1986 and is designed to work with Macintosh computers. The company does not have a large percentage of the market, and the only software tool that is able to challenge Adobe Illustrator is Laser Writer, a tool produced by Apple. Adobe Illustrator is a powerful tool that has a low learning curve. Despite this, it is famous for its level of precision. Many people have found Adobe Illustrator to be a useful alternative to complex design tools such as AutoCad.

The first advantages of Adobe Illustrator are, this application has advantages in terms of its nature that is integrated with many Adobe products in one unit called Adobe Creative Suite. This means, some Adobe Illstrator features are integrated with features in other Adobe applications, flexible in various other Adobe applications such as Adobe Photoshop, Adobe Lightroom, Adobe After Effects, Adobe Bridge, and various other Adobe products. Furthermore, one of the most prominent uses in AI software is making illustrations, but also the drop shadows that it provides are quite good and neat, so they are able to create illustration designs, fashion designs and cartoons that look more leverage. This graphic design application is capable of handling large RAW files. Print out feature produced by this graphics software is arguably very good, similar to one of the advantages and disadvantages of Corel Draw. In addition, this graphics software is able to print images that have high resolution without worrying about losing image resolution when the print out process occurs. AI also supports export to vector format with a good and accurate SVG (Scalable Vector Graphic) format. This means you can do graphical conversions made using this AI to SVG format directly from the AI application. Please note that there are differences in bitmaps and vectors.

Fashion design training using adobe illustrator at the Fashion Vocational School teachers in Semarang, and PKK FT UNNES fashion students, in order to respond to the curriculum at Fashion Design Vocational School as well as adding skills in designing with the coreldraw and adobe illustrator program. In the development of science, technology and art, it is a necessity that we respond by learning technology that supports the process of work, namely designing 
clothes with the program. Without setting aside the ability of the skills manually to sketch and design the corelraw and Adobe Illustrator fashion program is an effort for present and future generations where technology is inevitable for easy and dynamic creative processes. For this reason, increasing the ability of students needs to be encouraged with the right method, directed and focused.

\section{Conclusions}

Fashion design training using CorelDraw and adobe illustrator for the teachers of the Fashion Design Vocational School in the city of Semarang, and the Fashion Design students of the Department of Home Economic FT UNNES to respond to the curriculum at the Fashion Design Vocational School as well as add skills in designing with the CorelDraw and Adobe Illustrator program. In the development of science, technology and art, it is inevitable that we respond by studying technology that supports the process of creating, namely designing clothes with the program.

\section{References}

[1] Bastomi and Suwaji. (2003). Kritik Seni Bahan Ajar. Semarang: Jurusan Seni Rupa, Fakultas Bahasa dan Seni, Universitas Negeri Semarang.

[2] Hendratman, H. (2018). The Magic of Adobe Illustrator. Bandung: Informatika.

[3] Hopkins, J. (2010). Fashion Drawing. London: AVA Publishing.

[4] Susanto and Mikke. (2002). Diksi Rupa Kumpulan Istilah seni Rupa. Yogyakarta: Kanisius.

[5] Yoga. (2005). Desain Packaging dengan Adobe Illusstrator. Jakarta: Elex Media Komputindo.

\section{Appendix}

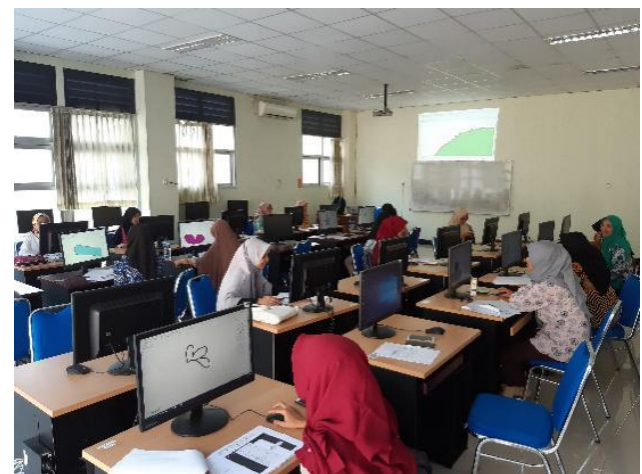

Figure 1. The atmosphere of design training with Corel Draw 


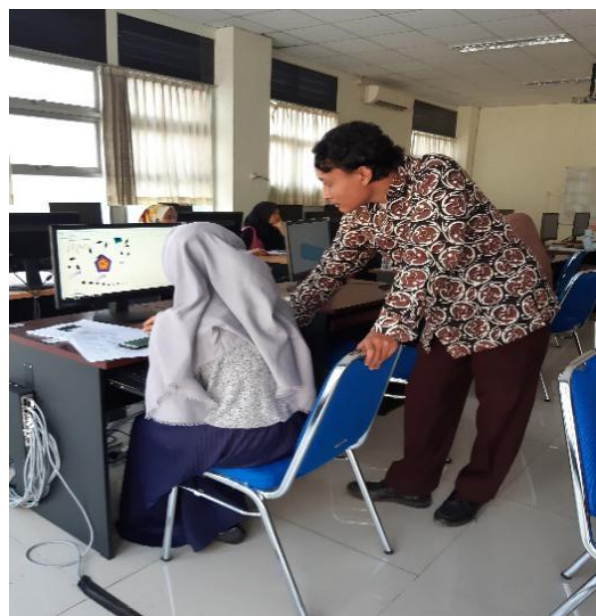

Figure 2. Submitting coreldraw material to participants

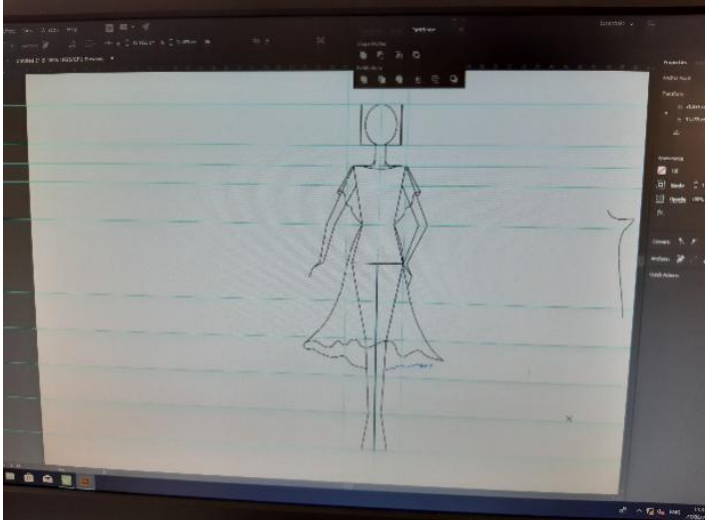

Figure 3. Example of the results of the Adobe Illustrator material by participants




Figure 4. Example of the results of the Adobe Illustrator material by participants
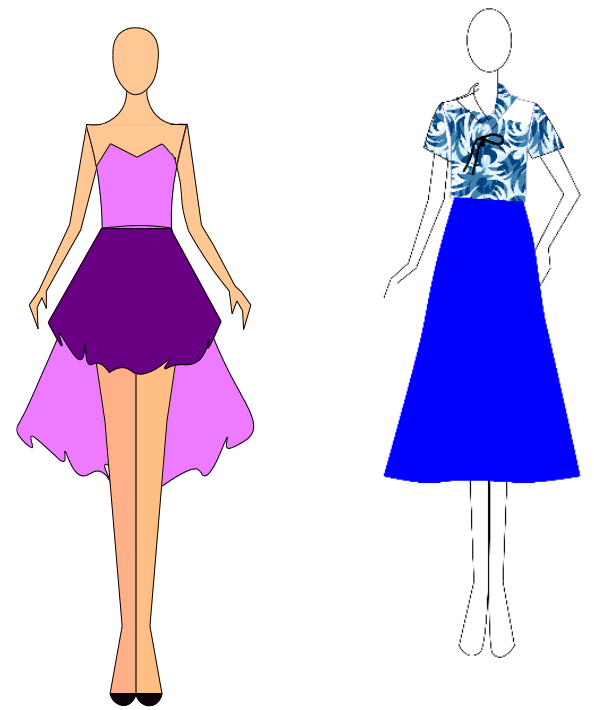

Figure 5. Example of the results of the Adobe Illustrator material by participants 